\title{
TOXIC ALVEOLITIS AFTER INHALATION OF A WATER REPELLENT
}

\section{GUIDO EPPING ${ }^{1}$, JOOP VAN BAARLEN ${ }^{2}$, and PAUL D.L.P.M. VAN DER VALK ${ }^{1}$}

${ }^{1}$ Medisch Spectrum Twente Hospitals, Enschede, The Netherlands

Department of Respiratory Medicine

${ }^{2}$ Medisch Spectrum Twente Hospitals, Enschede, The Netherlands

Department of Pathology

\begin{abstract}
Inhalation of fluorocarbon polymers can cause pulmonary toxicity. Although multiple cases of lung injury have been reported, cellular characterization of the associated alveolitis occurring acutely after inhalation is limited. We report the case of a previously healthy woman who presented at our Emergency Department with an acute pneumonitis following inhalation of a fluorocarbon polymer-based rain-proofing spray. Bronchoalveolar lavage (BAL) performed shortly after the presentation showed an elevated total cell count, with a high proportion of neutrophils (58\%) and eosinophils (9\%). In addition, a lipid stain (Oil-Red-O-stain) showed a high level of lipid laden macrophages, a marker that could reflect a direct toxic effect of the spray on alveolar cells. The patient made a full recovery after four days of in-hospital observation with supportive care.
\end{abstract}

Key words:

Water repellent, Toxic alveolitis, Acute interstitial pneumonitis, Broncho-alveolar lavage, Oil-Red-O-stain

\section{INTRODUCTION}

Waterproofing sprays contain a mixture of solvents, propellants (propane, butane, isooctane) and the agent acting as a water repellant (fluorocarbons, silicone resins) [1,2]. Inhalation of waterproofing sprays, specifically those containing fluorocarbons, has been strongly associated with acute lung injury. Symptoms typically include dyspnoea with a dry cough and an acute febrile and flu-like disease [1]. Radiographic findings range from scattered infiltrates to diffuse alveolar consolidations with ground-glass opacity changes [3].

It is critical to distinguish this fluoropolymer-linked syndrome from the toxic response associated with inhalation of fluorocarbon monomers or intermediate temperature fluorocarbon thermal degradation products. The selflimited syndrome associated with the latter exposure is marked by flu-like illness clinically resembling zinc oxidecause metal fume fever and is thus named 'polymer-fume fever' [4]. Polymer fume fever typically occurs in industrial outbreaks and often is associated with inhaling the fumes of contaminated cigarettes. In contrast, fluorocarbon waterproofing spray inhalation injury is typically due to consumer products used in the household, is not associated with contaminated cigarettes, and can be life-threatening even following a fairly brief exposure [3-6]. Outbreaks have occurred around the world, including in the Netherlands $[2,5]$. We report the case of a young woman presenting with a similar syndrome after impregnating her shoes

Received: May 18, 2011. Accepted: July 22, 2011.

Address reprint request to G. Epping, Haaksbergerstraat 55, 7513 ER, Enschede, The Netherlands (e-mail: G.Epping@mst.nl). 
with a water repellant spray. In this case we had the opportunity to perform bronchoalveolar lavage early in the course of the illness, thus characterizing the cellular constituents of the pneumonitis at the alveolar level.

\section{CASE REPORT}

A 36-year-old, previously healthy Caucasian woman who worked as a board secretary presented at the emergency department of our hospital. She was a current smoker. She was sent on to our hospital by her general practitioner with a suspected pneumonia. She presented herself with an acute onset of dyspnoea, a dry cough and a high grade fever with a temperature of $39.5^{\circ} \mathrm{C}$. These complaints were accompanied by generalized muscle ache and headache. Within an hour she felt nauseated and started vomiting. At our emergency department she reported possible exposure to a waterproofing spray about one hour before the start of her complaints, a history that had not previously been elicited. Indeed, she only provided this information after specifically being asked whether she had had contact with chemicals, emphasizing the importance of a thorough history taking. She obviously didn't see a relation between the exposure to the spray and her symptoms. She had carried out the impregnation of her shoes indoors in a room of about $20 \mathrm{~m}^{2}$, with the windows closed. She had not noticed any irritation while using the spray. Moreover, she had used the same spray previously under similar conditions without any accompanying complaint.

On physical examination the patient was frankly dyspnoeic, with a respiratory rate of 22 breaths per minute and a peripheral oxygen saturation of $89 \%$ while breathing room air. She had a tympanic temperature of $38.5^{\circ} \mathrm{C}$. Auscultation of the lungs revealed normal breathing sounds without rhales or crackles appreciated. The remainder of the physical examination was unremarkable. She was not able to complete sentences without taking a breath.

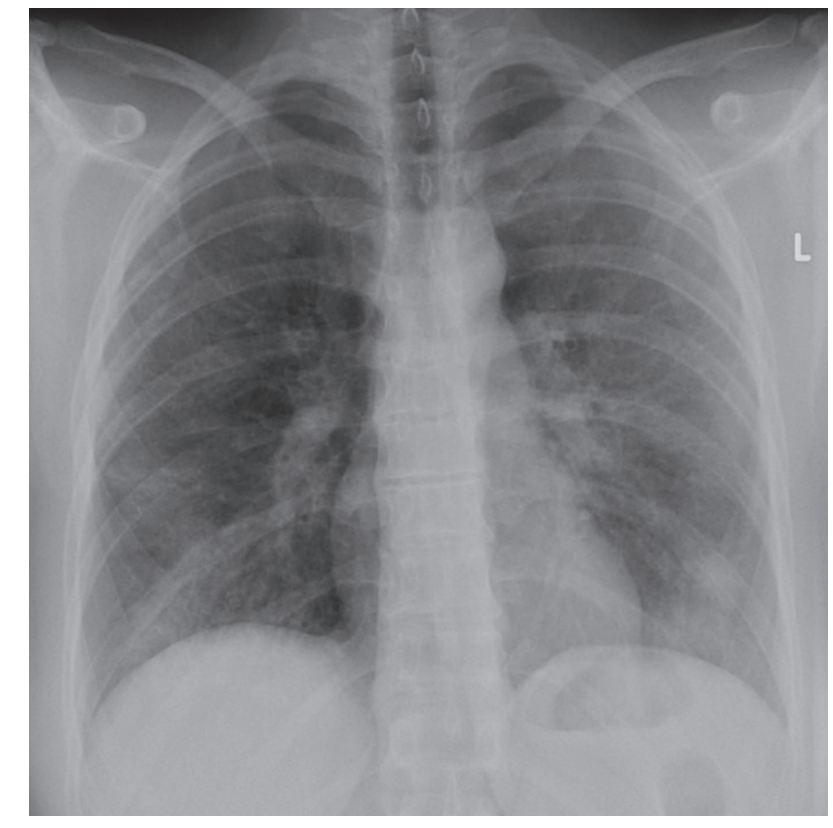

Photo 1. Chest X-ray (PA view) at presentation, demonstrating a pattern of bilateral, diffuse reticulation, with no signs of pleural fluid or enlargement of the heart.

Laboratory investigation showed an elevated white

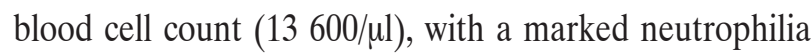
(12 600/ $\mu$ l). Other laboratory results, including peripheral eosinophil count and C-reactive protein, were normal. The routine chest-X-ray showed bilateral, diffuse, interstitial opacifications (Photo 1).

With a differential diagnosis including both community acquired pneumonia (the referring diagnosis) and an acute toxic pneumonitis due to water-proofing spray inhalation, we performed a high-resolution chest CT. The HRCT showed extensive ground glass opacity changes with an upper lobe predominance and areas of alveolar consolidation, symmetrically in both lungs (Photo 2). In light of the CT, approximately 8 hours after presentation to the Emergency Department we performed a bronchoscopy with a broncho-alveolar lavage (BAL) using $120 \mathrm{ml}$ of saline. The bronchial tree showed no abnormalities. The BAL fluid showed an elevated total cell count with a high proportion of neutrophils $(58 \%)$ and eosinophils (9\%) (Table 1 and Photo 3). A lipid 


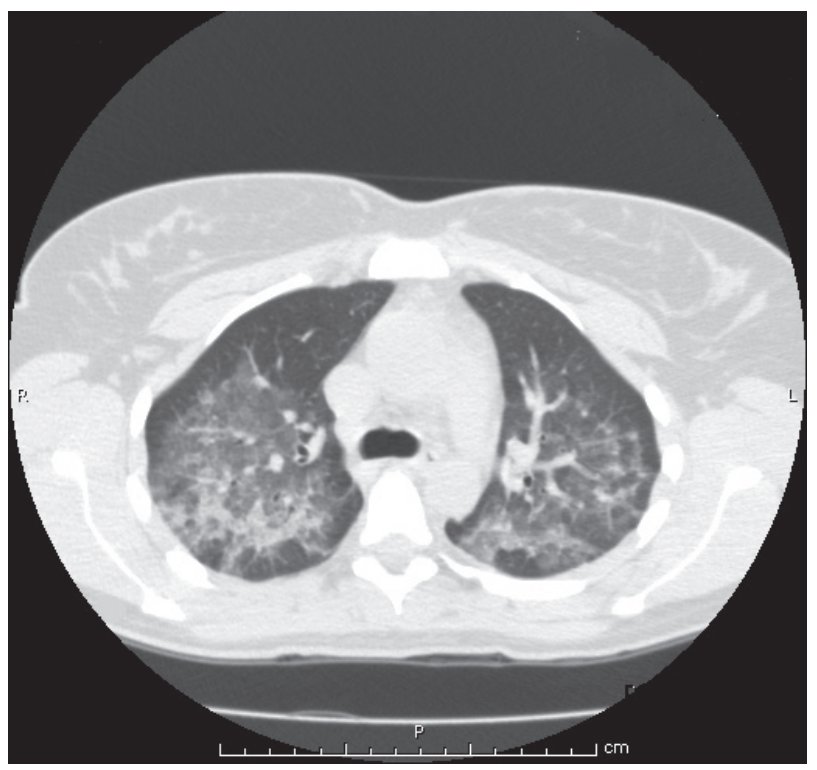

Photo 2. HRCT of the thorax 8 hours after presentation showed extensive, symmetrical ground glass shadowing with upper lobe predominance and areas of alveolar consolidation.

stain (Oil-Red-O-stain) demonstrated the presence of frequent lipid-laden macrophages (Photo 4). Late blood and BAL cultures were negative for both aerobic and anaerobic bacteria, mycobacteria and fungi; and further BAL fluid testing was negative for both atypical bacterial (Legionella pneumopila, Mycoplasma pneumophila and Chlamydia pneumophila) and viral pathogens (Cytomegalovirus, Influenza A/B virus, Parainfluenza 1/2/3/4 virus, Adenovirus, Respiratory Syncytial Virus, Rhinovirus, Human Metapneumovirus).

Table 1. Immunological examination of BAL fluid

\begin{tabular}{lcc}
\hline $\begin{array}{c}\text { Cell } \\
\text { differentiation }\end{array}$ & Number & $\begin{array}{c}\text { Reference value } \\
\text { (smokers) }[13,17]\end{array}$ \\
\hline Erythrocytes & $45.8 \times 10^{5} / \mathrm{ml}$ & $1.7 \times 10^{5} / \mathrm{ml} \pm 1.1$ \\
Leucocytes & $36.4 \times 10^{5} / \mathrm{ml}$ & $2.3 \times 10^{5} / \mathrm{ml} \pm 1.2$ \\
Eosinophils & $9 \%$ & $0.4 \pm 0.6 \%$ \\
Neutrophils & $58 \%$ & $1 \pm 1 \%$ \\
Macrophages & $30 \%$ & $96 \pm 3 \%$ \\
Lymphocytes & $3 \%$ & $3 \pm 2 \%$ \\
CD4/CD8 ratio & 2.4 & $0.5-1.5$ \\
\hline
\end{tabular}

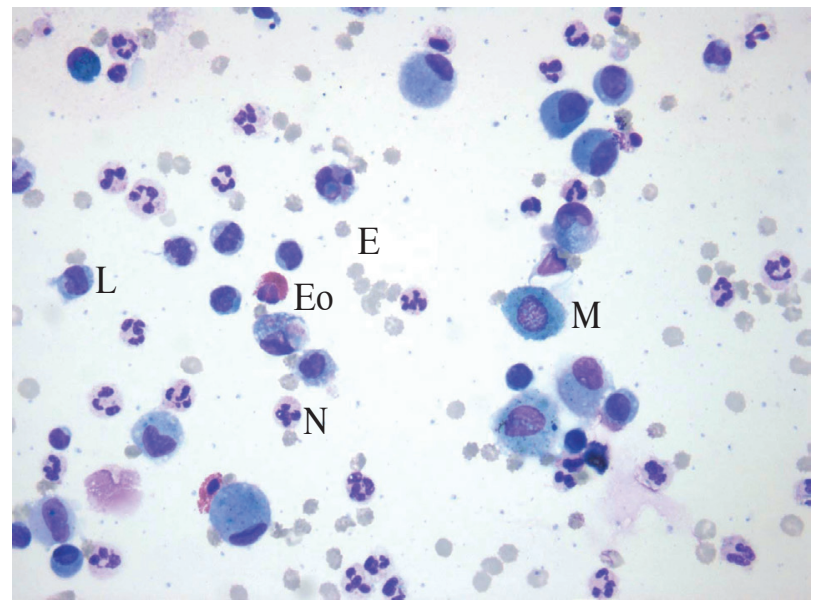

E - Erythrocytes, Eo - Eosinophils, N - Neutrophils, M - Macrophages, L - Lymphocytes.

Photo 3. Giemsa staining of BAL fluid, showing different cell types.

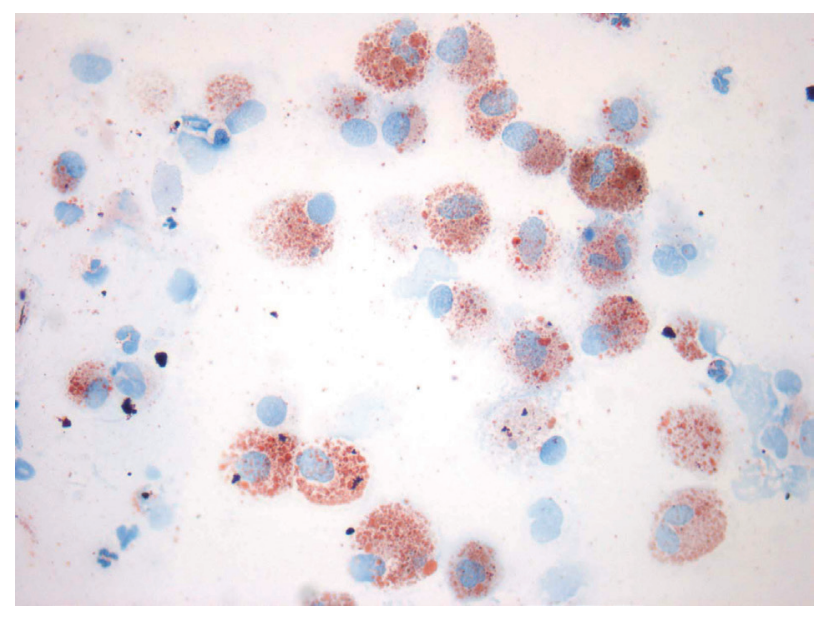

Photo 4. ORO stain of BAL fluid. Lipid particles in the vacuoles of the macrophages stain bright red.

We treated the patient supportively with supplemental oxygen and anti-emetics. We discontinued the corticosteroids and bronchodilators initiated as an outpatient. She made a full recovery, after 4 days of in-hospital observation. The chest X-ray normalized. Lung function testing, including airflows, total lung capacity, and diffusion capacity (DLCO), performed in an out-patient service 2 weeks after discharge was within normal limits for all values. 


\section{DISCUSSION}

Inhalation exposure to waterproofing sprays containing fluorocarbon polymers is a well known cause of an acute toxic pneumonitis, but the mechanism of injury remains obscure. Several hypotheses have been suggested. One accretive theory is that the polymer may exert its "waterproofing effect" on the alveolar surface, thereby modifying the alveolar surface tension and disrupting surfactant, thus causing alveolar collapse and impairment in gas exchange [7]. Alternatively, a direct toxic effect on alveolar cells has been demonstrated, through blockage of the Krebs cycle leading to cell death [8]. In animal studies, exposure to impregnating sprays lead to necrosis of type I alveolar cells, alveolar hemorrhage, and alveolar edema; an inflammatory cellular response was only a minor pathological finding [9]. Other experimental animal data suggest that the severity of pulmonary complications due to inhalation of waterproofing sprays is related to particle size [10].

Most likely, some form of biotransformation is required for the chemical compounds of the spray, to cause toxic cell injury. The cytochrome P450 (CYP) superfamily of enzymes is the main system involved in the initial biotransformation of the chemicals. It is in this initial phase that the toxic, reactive metabolites arise. When these toxic metabolites are not readily removed by protecting systems, they may cause cell injury and death. In that case biotransformation can become 'bio-activation'. Interestingly, both the expression of the CYP enzymes and the activity of the protecting systems vary inter-individually [11]. This might explain the different effects of toxin inhalation among individuals.

There are only limited published data regarding the bronchoalveolar lavage fluid in the acute phase after exposure to waterproofing sprays. In an animal study, high numbers of erythrocytes were found in the BAL fluid of the exposed animals [9]. A French report showed an inflamed bronchial tree with a hemorrhagic BAL fluid [12]. In line with the results from these former studies we also found high levels of erythrocytes, in the BAL fluid, in the acute phase after exposure to the water repellent. This might therefore actually represent an effect of the exposure to the spray, in line with the hemorrhagic alveolitis seen in the case of the use of cytotoxic medication [13].

In our study the white cell count in the BAL fluid was very high. In the differential count of the leucocytes using a Giemsa stain we found a high level of eosinophils, and a very high level of neutrophilic granulocytes. Consistent with our results, a study from Japan with a bronchoscopic investigation performed three days after exposure showed an evident neutrophilia in the BAL fluid [14].

We are the first to perform an additional lipid stain (ORO stain) in the setting of an inhalation trauma. With the ORO stain we demonstrated high levels of fat particles in the macrophages. We are unsure whether the lipids in the BAL fluid represent phospholipid inclusions due to disruption of surfactant [15] or a direct toxic effect on the alveolar cells with increased cell death [13]. On the other hand it might represent the lipid-rich component in the water repelling spray itself $[13,16]$. This subject needs further investigation. The prognosis of a toxic alveolitis after inhalation of a fluorochemical-based repellant is generally good with a full recovery in several days without treatment [8]. Evidence in support of treatment with corticosteroids is at the level of case reports. There are no placebo-controlled trials available. However, cases with persistent cough and dyspnoea consistent with fibrotic changes in the lung have been reported in untreated patients. Patients treated with corticosteroids did not progress to fibrosis. Therefore practice guidelines advise treatment with corticosteroids $[5,8]$.

We decided not to treat our patient because of the lack of evidence. She made a full recovery after four days of in-hospital observation with supportive care. Pulmonary function tests performed in an out-patient service, 2 weeks after discharge, were normal. One year after the incident she is doing fine, without pulmonary problems. In conclusion this report emphasizes the importance of a thorough history taking. It is clear that patients don't 
necessarily see the relation between an exposure with household products or occupational exposures and their medical complaints. Moreover, the present report is the first to show the results of a bronchoalveolar lavage with cellular differentiation in the acute phase of a toxic alveolitis due to a water repellent spray. This can help to further understand the still unresolved toxic mechanism by which water repellants cause a toxic alveolitis.

\section{REFERENCES}

1. Smilkstein MJ, Burton BT, Keene W, Barnett M, Hedberg $\mathrm{K}$, Fleming D, et al. From the Centers for Disease Control and Prevention. Acute respiratory illness linked to use of aerosol leather conditioner — Oregon, 1992. JAMA 1993;269(5): 568-9.

2. Groot R de, Vries I de, Meulenbelt J. Sudden increase of acute respiratory illness after using a spray product to waterproof clothing and shoes. J Toxicol Clin Toxicol 2004;42(4):A45,443.

3. Wallace GMF, Brown PH. Horse rug lung: toxic pneumonitis due to fluorocarbon inhalation. Occup Environ Med 2005;62; 414-6.

4. Cormican LJ, Rees PJ. Hill walkers' lung. Respiration 2006; 73:836-9.

5. Bonte F, Rudolphus A, Tan KY, Aerts JG. Severe respiratory symptoms following the use of waterproofing sprays. Ned Tijdschr Geneesk 2003;147(24):1185-8 [in Dutch].

6. Laliberté M, Sanfacon G, Blais R. Acute pulmonary toxicity linked to use of a leather protector. Ann Emerg Med 1995;25:841-4.

7. Vernez D, Bruzi R, Kupferschmidt H, De-Batz A, Droz P, Lazor R. Acute respiratory syndrome after inhalation of waterproofing sprays: A posteriori exposure-response assessment in 102 cases. J Occup Environ Hyg 2006;3:250-61.
8. Smit AAJ, Heuvel van den M, Roos C, Zee JS. Toxic alveolitis caused by the inhalation of a leather impregnating spray. Ned Tijdschr Allerg 2004;5:188-92 [in Dutch].

9. Hubbs AF, Castranova V, Ma JYC, Frazer DG, Siegel PD, Ducatman BS, et al. Acute lung injury induced by a commercial leather conditioner. Toxicol Appl Pharmacol 1997;143:37-46.

10. Yamashita M, Tanaka J, Yamashita M, Hirai H, Suzuki M, Kajigaya H. Mist particle diameters are related to the toxicity of waterproofing sprays. Vet Hum Toxicol 1997;39: 71-4.

11. Delaunois LM. Mechanisms in pulmonary toxicology. Clin Chest Med 2004;25:1-14.

12. Testud F, Gabrielle L, Paquin ML, Descotes J. Acute alveolitis after using a waterproofing aerosol: apropos of 2 cases. Rev Méd Interne 1998;19:262-4 [in French].

13. Tötsch M, Guzman J, Theegarten D, Schmid KW, Costabel U. Bronchoalveolar lavage. Pathologe 2007;28:346-53 [in German].

14. Ota H, Koge K, Tanaka H, Akaishi T, Kikuchi K. Acute respiratory failure due to inhalation of aerosol water proof agent. Nihon Kokyuki Gakkai Zasshi 2000;38:485-9 [in Japanese].

15. Gurel O, Ikegami M, Chroneos ZC, Jobe AH. Macrophage and type II cell catabolism of SP-A and saturated phosphatidylcholine in mouse lungs. Am J Physiol Lung Cell Mol Physiol 2001;280:1266-72.

16. Gratadour P, Védrinne JM, Guillaume C, Gagnieu MC, Motin J. Fat droplets within macrophages obtained by bronchoalveolar lavage: incidence and diagnostic value. Ann Fr Anesth Réanim 1993;462-8 [in French].

17. Hopkins SR, Schoene RB, Henderson WR, Spragg RG, West JB. Sustained submaximal exercise does not alter the integrity of the lung blood-gas barrier in elite athletes. J Appl Physiol 1998;84:1185-9.

This work is available in Open Access model and licensed under a Creative Commons Attribution-NonCommercial 3.0 Poland License - http://creativecommons.org/ licenses/by-nc/3.0/pl/deed.en. 